\title{
Characterization of Reinforced Carbon Composites with Full Field Measurements: Long Gauge Length Compressive Apparatus
}

\author{
Mathieu Colin de Verdiere ${ }^{1,2^{*}}$, Alexandros A. Skordos ${ }^{1}$, Andrew Walton ${ }^{3}$ \\ ${ }^{1}$ Composites Centre, Cranfield University, Cranfield, UK; ${ }^{2}$ Fluid Structure Interaction, School of Engineering, Southampton Univer- \\ sity, Hampshire, UK; ${ }^{3}$ Cranfield Impact Center, Cranfield, UK. \\ Email: *mathcolinv@hotmail.com
}

Received September $2^{\text {nd }}, 2012$; revised October $15^{\text {th }}, 2012$; accepted October $27^{\text {th }}, 2012$

\begin{abstract}
A new compressive testing apparatus is developed and used in this research. It has long gauge length to allow digital image correlation monitoring and anti buckling guides to prevent buckling. It allows the optical recording of strains and displacements. The novel setup is used to study the compressive response of tufted and untufted Carbon non crimp fabric composites with full field measurements. Experimental results show that the specimens are not bending in the apparatus under compression. Results also show reduced strain concentrations and a large strain field that provides a good environment for material compressive stiffness characterization. The test proves particularly successful for bias direction layup of $[+45 /-45]$ for which large damage mechanism occurs. However for [0/90] specimens a scatter in compressive ultimate strength was noticed which is due to the difficulty to prepare specimens with best minute accurate geometry. The compressive apparatus has shown to be a good alternative to existing setups and to provide significantly more information as well as having the possibility to be used in dynamics with a drop tower.
\end{abstract}

Keywords: Carbon Composite; Compression Testing; Full Field Measurements

\section{Introduction}

Composite structures undergo complex deformations depending on the laminate design, part geometry and the loading itself. Such structures are subjected to in-plane tension, shear, compression and out of plane stresses. In order to simulate the material response for structural design purposes, tensile, shear, compression, and out of plane data are required and gathered from tests. Compression testing remains difficult compared to other sets of tests as specimen misalignments, material defects, and poor specimen geometry lead to premature catastrophic failure at the specimen level not representative of the material itself. Compressive loading of polymeric composites is often characterized by damage occurrence such as micro buckling (axial) and matrix cracking (bias direction) mechanism. Many researchers investigated these responses through better compressive apparatus designs allowing better specimen characterization. Meanwhile in the last ten years digital image correlation (DIC) has gain accuracy and a more trouble-free usage due to better algorithms and optics. It can provide full field information

${ }^{*}$ Corresponding author. exceeding the strain gauges elongation. The method is often used in tension to characterize polymeric materials through failure strain and stiffness measurements. As stiffness and damage in compression is much different than in tension the need to investigate this difference with a full field experimental approach is of interest. Current compressive apparatus do not allow good use of full field measurements in compression as the specimens are often too small or direct view is diverted by the compressive apparatus. In this research a new compressive testing setup was designed that allowed the use of full field digital image correlation on polymeric composites and provided added information on compressive failure, compressive strain, compressive stiffness and compressive damage behavior. The capacity of the apparatus has been introduced briefly in [1] but is presented in this paper in greater detail. The paper reviews existing compressive apparatus first and then describes the new compressive design. Subsequently, results using a modified standard apparatus and the new compressive apparatus on standard and tufted non crimp fabric composites are reported. Finally, the results are discussed and compared to the published literature. Conclusions on the validity of the tests and the material response are presented. 


\subsection{Existing Methods for Compressive Loading Test of Composites}

Compressive data are difficult to acquire because fibrous composite material undergo micro-buckling, splitting, inter-laminar shear, and the specimen itself is likely to buckle. Furthermore, load and specimen misalignments are possible throughout a test which would affect the strain gage readings and failure strength.

The existing compressive testing set ups are classified in three different categories depending on the manner the load is introduced in the specimen.

- The first category is called the end loading method and introduces the load directly at the end of the specimen; it is described in standard D695-91 [2]. The standard recommends a long specimen gauge length and use of anti buckling guides. This set up is cost effective and versatile but has the disadvantages of not being able to obtain a complete stress strain surve and of high sensitivity to specimen geometry [3]. Westberg [4] recommends the addition of an end cap at the specimen top to prevent brooming.

- The second category of compressive set ups is the shear loading method which introduces the load in shear by clamping the short tabbed specimen in grips. This type of setup is described in standard D34109/D/ D34010M-03 [5]. The apparatus is called the Celanese or the IITRI rig (Illinois Institute of Technology of Research Institute).

- More recently a final category of setups emerged as it was found that combinations of end and shear loading methods reduced stress concentrations at the tab tip and at the loaded end [6]. The RAE rig used this method in the early eighties [7] but in recent times new advanced compressive apparatus such as Wyoming CLC (combined loading compression) [8] and ICSTM (Imperial College London) $[9,10]$ using combined loading were developed and led to standard D6641/D6641M [11].

Comparison of compressive testing methods via round robins or more limited research occurred more than 15 years ago $[3,4,7,12-15]$ and showed some contradicting trends. Seng [14] established that the Celanese apparatus provided lower compressive strength than other testing methods, which opposed the findings of Aoki [16]. Woolstencroft [17] showed that the RAE apparatus conferred a compressive strength near the true value of the material. The end loading method was reported to be superior to others and yielded a higher compressive strength [6] for thick specimens. Westeberg [4] and Abdallah [12] found that the differences between shear loading and end loading methods were small in their optimum configurations, as long as the end did not crush and that in either case the tabs did not debond [12]. Fi- nally specimen preparation was found to be critical to achieve optimum compressive testing conditions $[4,12$, $16,17]$.

\subsection{Notes on Experimental Compressive Testing}

Loading introduction can lead to stress concentrations that affect strain readings on small specimens, leading to improper material characterization. Adams [12] found that shear loaded specimens had higher stress concentrations at the tab tip while end loaded specimens showed more stress at the end loaded tip.

As the specimen becomes thicker, stress concentrations occurred at the end tabs making the estimation of stiffness difficult and lowering the overall compressive strength [14]. Bogetti [18] found that end effects on the IITRI apparatus could modify the Young's Modulus to $30 \%$ of its true value. Therefore Harper [3] recommends the use of longer specimens. Adams [12] acknowledged that specimen gauge length had little influence on compressive strength, but then the failure may occur away from the strain gage location.

Nisitani [19] found that strength was constant from 3.2 to $12.7 \mathrm{~mm}$ specimen gauge length using a Celanese rig. Small gauge length specimens provided a value close to the true strength but bared more difficulties with strain measurements. Salvi [20] tested off axis composite specimens in compression and recommended long specimen gauge length with anti-buckling guides for proper characterization. It is understood that longer gauge length provides a uni-axial strain field in the middle of the specimen (Figure 1).

According to Harper [3] misalignments create a bending moment in the specimen that makes the strain recording on both sides of the composite different giving improper stress strain curve and modulus. Similarly Woolstencroft [7] with the RAE rig found that in-plane misalignments reduced the compressive strength by $50 \%$.

After reviewing the literature, it is understood that

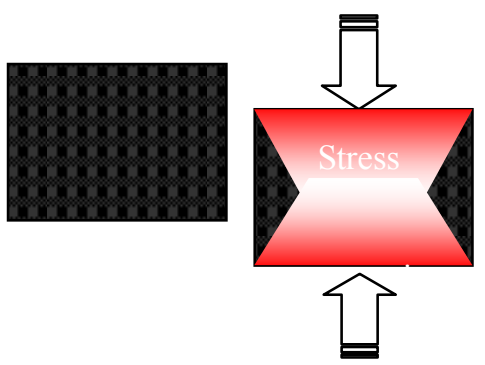

(a) Small specimen unloaded

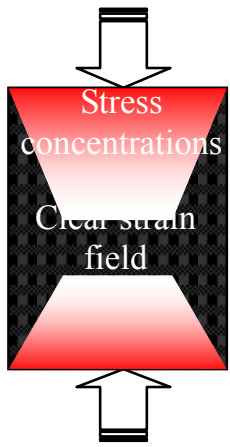

(c) Longer specimen loaded
Figure 1. Stress concentrations in compression. 
most compressive apparatus have been designed specifically to reduce the scatter in ultimate strength of the material, and only in secondary for compressive modulus or strain measurements. For practical reasons many researchers use an extensometer to characterize the specimen compressive displacement from which they compute an overall strain to avoid gluing a small strain gauge on such reduced specimen size.

\subsection{Compressive Failure and Damage}

Composite materials have lower properties in compression than in tension because of catastrophic instability via microbuckling, inter laminar shear failure [10], and stress concentrations near the tabs [19]. Failure is initiated by local shear, followed by delamination and buckling of layer [3,21]. Berbinau [15] found that kink bands were initiated at the laminate free edge, at a void, or at points of high fibre curvature. As microbuckling occurs due to the buckling of fibres whilst kink bands are formed at peak stress when the matrix is deformed plastically [22]. The best model to predict microbukling was the Xu-Reifsnider model [23] and to predict kink bands the Budiansky model [22].

\section{Experimental Procedures and Apparatus}

\subsection{New Compressive Testing Apparatus}

Light reflection on the specimen can make the calibration of the optical system difficult and time consuming. Therefore the new compressive apparatus is designed to provide maximum and regular enlightenment of the sample (Figure 2). The specimen is loaded via end and shear loading at the bottom end, while it is simply end loaded at the top end. In order to improve the end load introduction in the composite and reduce stress concentration, 1.5 $\mathrm{mm}$ aluminum tabs are added at each end of the specimen. To prevent any delamination or splitting a cap is added on top of the composite. Anti-buckling guides are composed of steel struts $3 \times 5 \times 50 \mathrm{~mm}$ (Figure 3).

Possible specimen thicknesses that can be tested vary

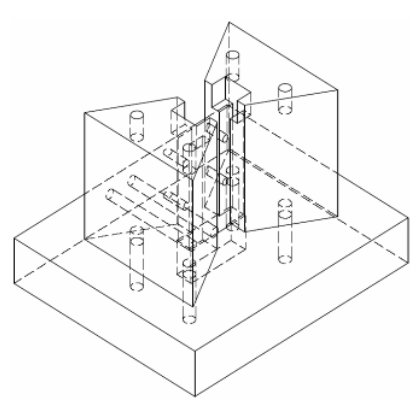

(a) Drawing view

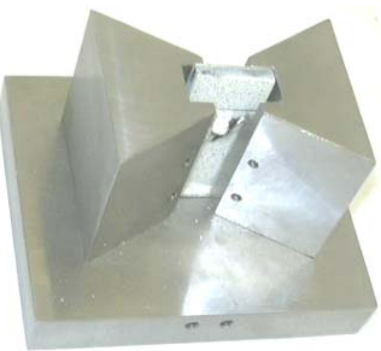

(c) Apparatus with specimen
Figure 2. Long gauge length compressive rig. from 1 to $4.5 \mathrm{~mm}$. The specimen length is $80 \mathrm{~mm}$, the width $25 \mathrm{~mm}$ and the gauge length can vary from 70 to $60 \mathrm{~mm}$.

\subsection{Specimens}

Specimens are manufactured from carbon fibres and epoxy resin. TENAX HTA $6 \mathrm{~K}$ carbon fibre arranged in a NCF (Non CrimpFAbric) of $540 \mathrm{~g} / \mathrm{m}^{2}$ areas density with a $+/-45$ degrees bi-diagonal architecture are used. Some of the specimens are reinforced through the thickness by tufting with a $1 \mathrm{~K}$ carbon thread and $5 \times 5 \mathrm{~mm}$ density. The matrix is RTM6 resin. The specimens are made via resin infusion at high temperature. Specimens are sprayed in white and black paint to form a speckle pattern (Figure 3). Paint dot positions are recorded and interpreted throughout the tests with 2 cameras. The layups and size of specimens are reviewed in Table $\mathbf{1}$ for the different test configurations.

\subsection{Strain and Displacement Recording}

Strain gauges measurements are limited by the gauge size and the maximum deformation they can hold before failing and the necessity of gluing and wiring them. An alternative solution such as DICM is more time consuming in data post processing but it provides further information as strain and displacement are monitored on the whole surface. Optical strain field measurement requires the use of one camera (in 2D) or two cameras (in 3D); the latest provides the opportunity to check for out of plane deformation with positions and angles of the cameras computed via pictures recorded with a calibration target (Figure 4(a)).

The camera position and light intensity are important features of the design of the new compressive set up (Figure 4). Optical recording provides vertical displace-

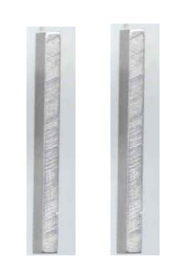
(a) Steel anti buckling guides
(b) End
cap

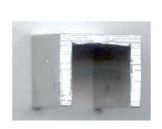

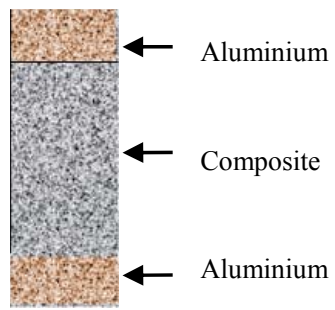

(c) Schematics of specimen with tabs and speckle pattern
Figure 3. Anti buckling guide cap and specimen.

Table 1. Apparatus and specimen used.

\begin{tabular}{cccc}
\hline Lay up & Specimen size & $\begin{array}{c}\text { Specimen } \\
\text { gauge lenght }\end{array}$ & $\begin{array}{c}\text { Specimen } \\
\text { numbers }\end{array}$ \\
\hline$[0 / 90]_{6 \mathrm{~s}}$ and $[+45]_{6 \mathrm{~s}}$ & $80-72 \mathrm{~mm}$ & $\pm 55 \mathrm{~mm}$ & 35 \\
\hline
\end{tabular}


ment on the specimen area. The large strain field also permits to analyze the specimen failure in compression throughout the loading using several strain extraction methods (Table 2). This permits to gain useful information such as possible bending or strain concentration on the specimen that could invalidate the tests. Displacement data can be extracted in specified locations such as top and bottom of the specimen from which an overall strain can be calculated. If bending or misalignments occur then the two extractions technique yields significant difference. Comparing the two measurements can be used to check that the specimen is not bending and that the test is valid.

\section{Experimental Results}

The long compressive apparatus provides a long area of interest that allowed the characterization of [0/90] and $[+45 /-45]$ tufted and untufted specimens. The strain field allows the identification of maximum strains regions which are in agreement with the locations of specimen failure. Tufted and untufted specimens are tested in axial compression on [0/90] specimens and bias direction compression on $[ \pm 45]$ specimens.

\subsection{Axial Behavior $[0 / 90]$}

\section{a) Untufted material}

Figure 5 describes the behavior of the untufted [0/90] specimen in compression. It is observed that the strain at failure is higher than the other extracted strains, which

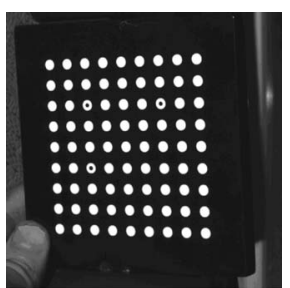

(a) Calibration target

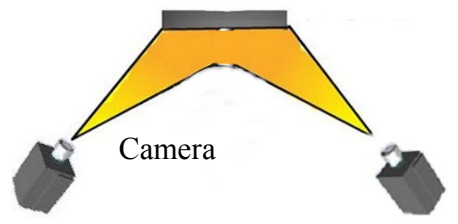

(b) Top view of full field strains recording on specimen
Figure 4. Optical strain recording set up.

Table 2. Different extraction methods.

\begin{tabular}{|c|c|}
\hline $\begin{array}{l}\text { Strains extraction } \\
\text { methods }\end{array}$ & Corresponding method \\
\hline Failure & The strains were extracted on the failure area \\
\hline Average centre & $\begin{array}{l}\text { The strains were average on the } \\
\text { whole specimen. }\end{array}$ \\
\hline $\begin{array}{l}\text { "Average displacement" } \\
\text { "global extensometer" }\end{array}$ & $\begin{array}{c}\text { The strains were calculated from the } \\
\text { displacement at the top and bottom of the } \\
\text { sample. }\end{array}$ \\
\hline $\begin{array}{l}\text { "Local central point" } \\
\text { or "middle" }\end{array}$ & $\begin{array}{l}\text { The strains were extracted in the middle of the } \\
\text { sample and were assumed to be similar to a } \\
\text { strain gauge. }\end{array}$ \\
\hline
\end{tabular}

means that the failure is relatively localized. The average displacement and the average centre strain are very close. Thus it is deduced that the specimen was not bending and that the test was therefore valid. The specimen cross section was observed with an optical microscope.

The failure modes identified are delamination, kink bands, matrix cracking and fibre breaking (Figure 6). The " 0 " plies can be observed in white and the " 90 " plies in dark grey. It can be observed that the non crimp plies have some waviness throughout the thickness of the materials even so they are not weaved. It can be also noticed that little damage occurs away from the failure area. Finally the 0 degrees fibers are rarely at a strict 0 degrees from the specimen axis.

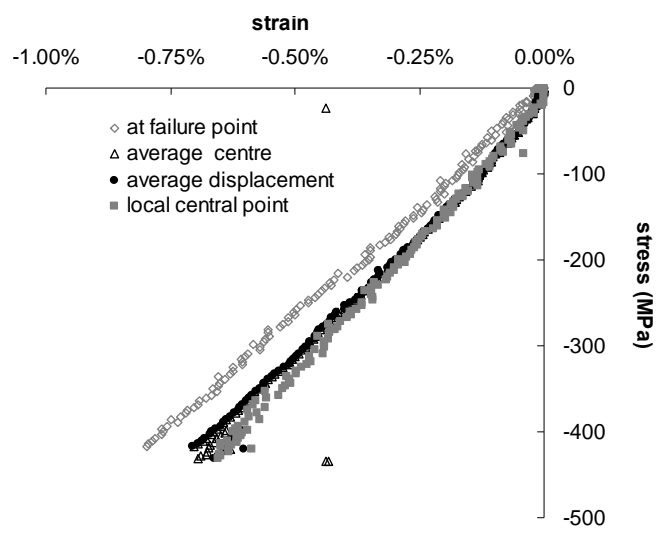

Figure 5. Compressive stress strain response of $[0 / 90]$ untufted specimens.

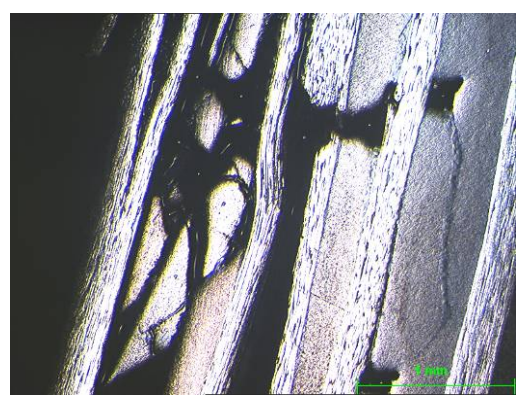

(a)

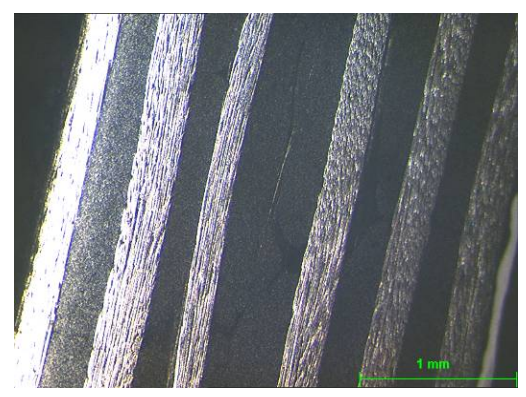

(b)

Figure 6. Optical microscope images of untufted [0/90] specimens; (a) specimen failure, (b) fibre waviness. 


\section{b) Tufted material}

Results of tufted specimens in compression are also monitored with the optical strain field apparatus. The specimen behavior at compressive failure is shown in Figure 7. On that sample the failure occurred near the top tabs on the monitored side. In most case the failure would occur in the middle of the specimen, also it was not always the case. The image show that failure was much localised (blue) and that after failure the rest of the specimen unloaded itself proof of some overal minor damage except at failure location.

Results also show that the specimen is not bending as the average calculated displacement strain and the average center strain are close (Figure 8).

The specimen was observed under a stereoscope. Figures 9 (a) and (b) shows the resin rich area caused by the through thickness tufts.

The global strain is used to compare and analyze the results. The global strain is an average of the strain in the gauge area.

This strain is preferred to the use of failure strain because the tufted specimen failure showed that failure could in some cases be localized on one side of the specimen due to the tufts holding the material together. The responses of the tufted and untufted composites in compression are illustrated in Figure 10.

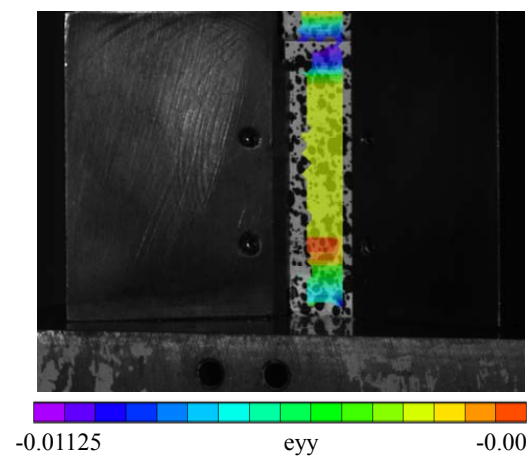

Figure 7. Strain field on the tufted specimen.

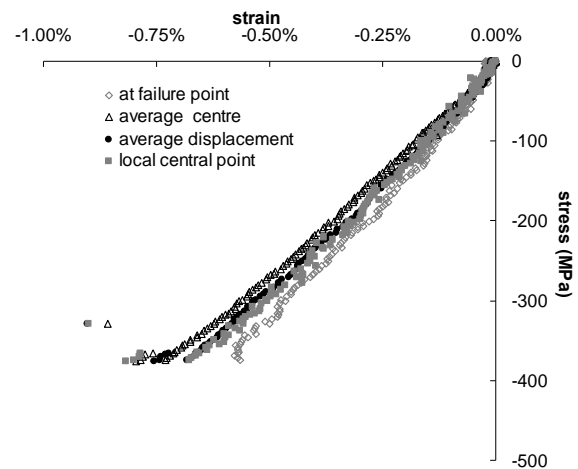

Figure 8. Compressive stress strain response of [0/90] tufted specimens.
Untufted materials show a stiffer and stronger response than the tufted NCF composites.

This is partly explained by the resin rich area at the tuft site which lowered the fibres volume fraction locally and the induced fibre misalignment. The data of the materials in compression are summarized in Table 3.

Micrographs of failure are illustrated in Figures 11 (a) and (b). Both specimen types show kink bands, large delamination, fibre failure and kinking. But the tufted specimen shows that the damage was smaller on the specimen surface but propagated through the specimen thickness. The untufted specimen shows more micro delamination and a more concentrated damage area.

\subsection{Compression in the bias direction $[+45 /-45]$}

In plane bias direction tests are commonly performed in tension following standard procedure with a laminate at $[+45 /-45]$. The new long gage length allow for compres-

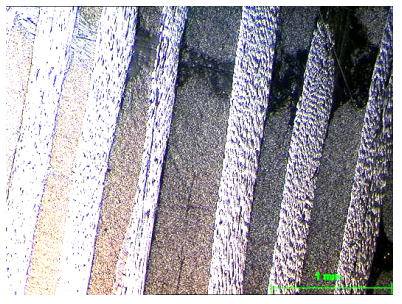

(a)

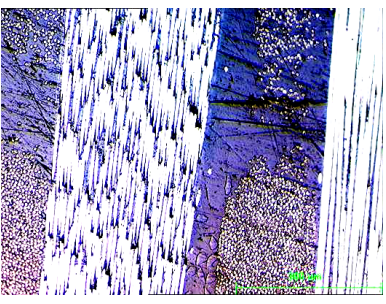

(b)
Figure 9. Through the thickness resin rich area due to the tuft (a) resin rich area and (b) resin rich area bigger magnification.

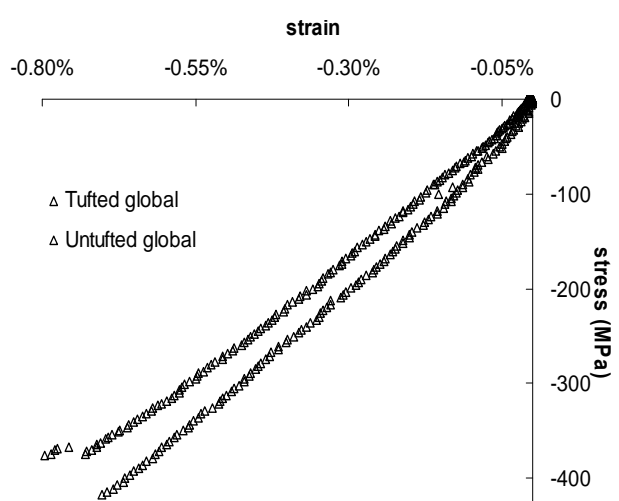

Figure 10. Comparison of [0/90]s tufted and untufted strain stress response.

Table 3. Mechanical properties.

\begin{tabular}{ccc}
\hline & Untufted & Tufted \\
\hline Compressive modulus (GPa) & 63 & 56 \\
Compressive ultimate strain (\%) & 0.70 & 0.71 \\
Compressive strength (MPa) & 418 & 374 \\
\hline
\end{tabular}


sive bias direction testing since the specimen gauge length is twice as long as its width. Effectively the [ \pm 45$]$ tows needs to slide freely relatively to one another to allow the shearing behavior to occur fully. On small specimens the width is often wider that the gauge length which means that then the tabs prevents the full bias direction shearing to occur fully. On the other hand the long specimen gauge length and conventional width of the new specimens permit such mechanism to occur and to be monitored fully. Again different information is extracted from the strain field to follow the specimen compressive shear response.

\section{a) Untufted material}

The untufted specimen response is illustrated in Figure 12(a). The strains recorded in the specimen middle and at failure are similar because failure occurs in the middle of the specimen. Lower strain was measured before ultimate failure as some of the specimen tends to relax when part of it is failing. This difference is explained by the fact that failure is localized to a specific area of the specimen.

\section{b) Tufted material}

The strain recording on the tufted specimen is similar to the untufted specimen and can be seen in Figure 13.

Difference between middle and failure strain indicates that the shear failure does not take place in the middle. Large strain at failure compared to the overall strain

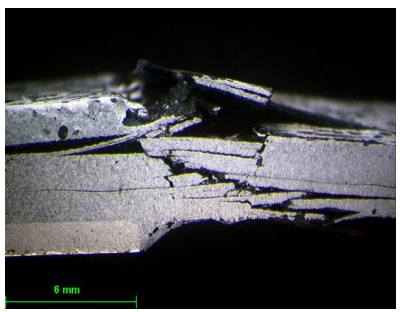

(a)

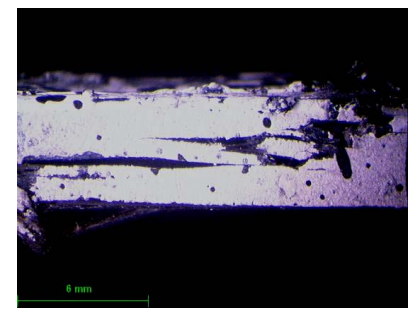

(b)
Figure 11. (a) Untufted specimen; (b) Tufted specimen.

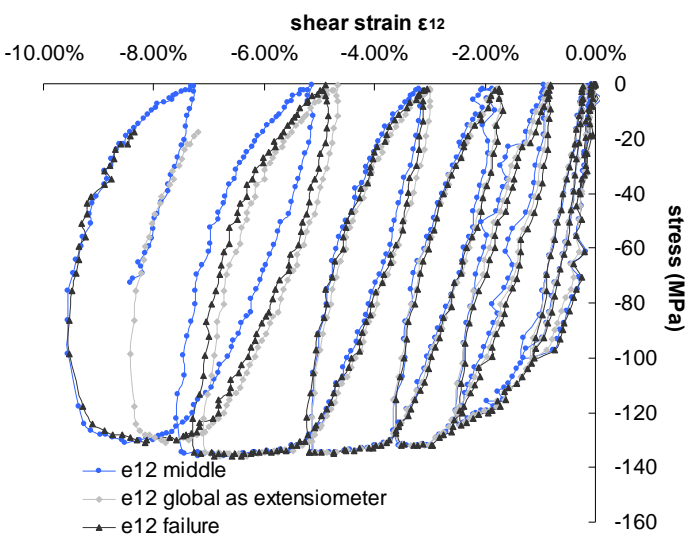

Figure 12. Stress strain response in the bias direction; untufted. highlights the localization of the damage area.

c) Comparison between tufted and untufted on \pm 45

Comparison of the tufted and untufted material is illustrated in Figure 14. The tufted material shows a stronger response meaning that the specimen will absorb considerably more energy during failure. The strain at failure was similar for the two materials.

The untufted specimen shows large shear delamination of the layers through the thickness with some shear failure and delamination of the tows on the surface (Figure 15). Tufted specimens show less severe delamination on the surface and through the thickness. Nevertheless delamination is well spread through the thickness.

\section{Discussion}

The work of Bogetti [18] illustrates that the compressive Young's Modulus could be up to $30 \%$ off its true value with the IITRI apparatus due to stresses and strains concentrations. Part of the literature recommends the use long gauge length to avoid stress concentrations; such a configuration is particularly promising combined with the use of DICM.

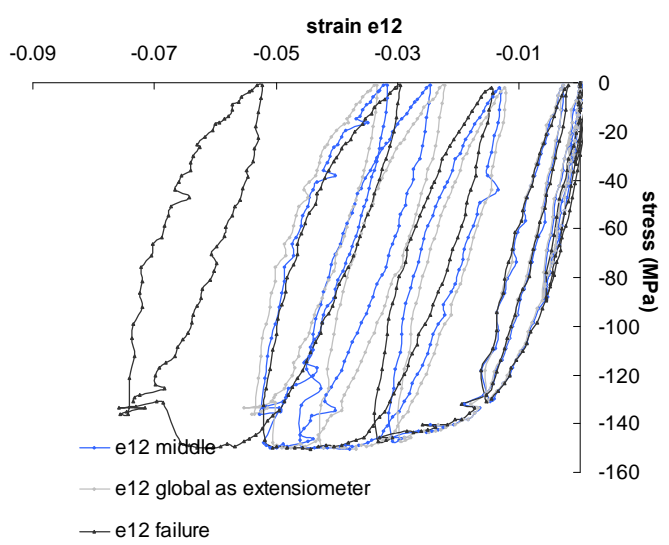

Figure 13. Stress strain response in the bias direction; tufted.

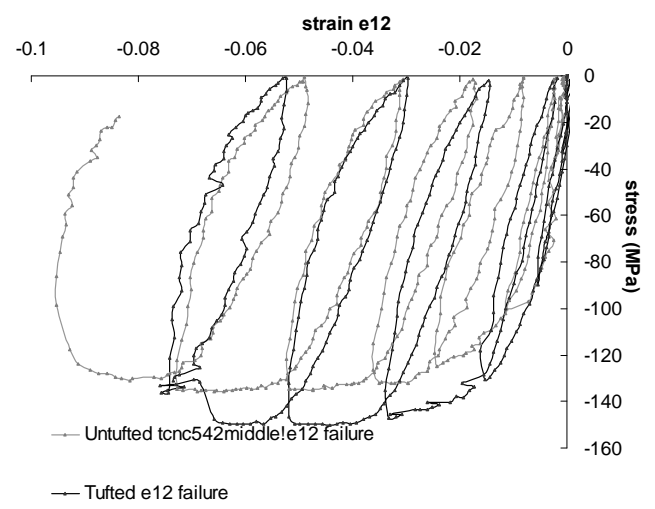

Figure 14. Comparison stress strain response in the bias direction for tufted and untufted composites. 


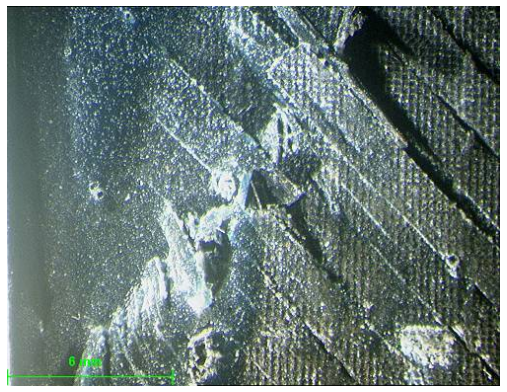

(a)

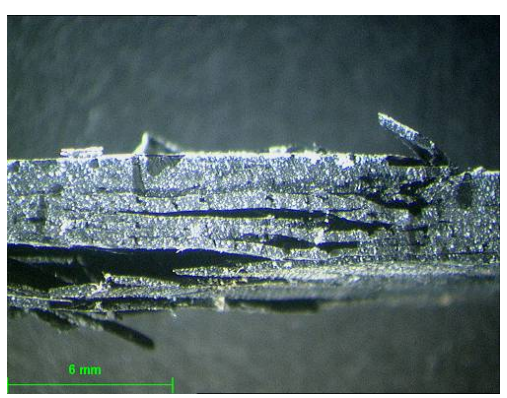

(b)

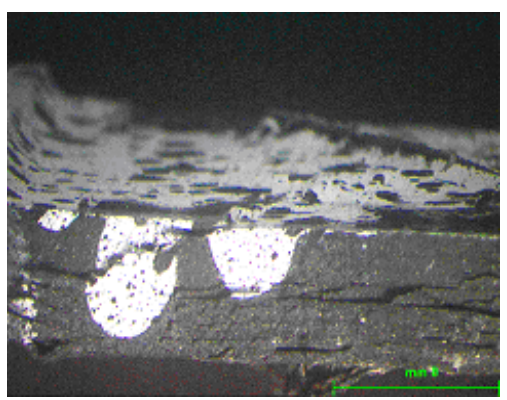

(c)

Figure 15. Image of tufted and unutfted specimen in bias direction failure (a) surface untufted damaged area; (b) large through the thickness delamination for untufted specimen, tufted specimen limited delamination of the tows, localised fibers failure on the surface.

The compressive apparatus provides information that is not obtainable in compression with standard setups with strain gauges or extensometer recording equipment. This is due to the damaging nature of compressive response that is rather complex and particularly well monitored by the long gauge length and full field measurements. Full field measurements permit to distinguish between different areas of the material and provide significantly more information that allows checking that the specimen does not bend under compressive loading. The DICM method is an adequate tool to measure the material response with the new compressive apparatus. In addition to the test validation, the tool provides full stress strain curves for both axial and bias direction compressive loading.

The apparatus is understood to provide complete com- pressive bias direction characterization that was not possible in previous setups as the gauge length relative to the specimen width was too small.

The new setup proves to be reliable on cross ply laminates as on [0/90] laminate the ultimate strength can have some scatter. The cap end and added tab improve load introduction in the specimen preventing any splitting or brooming. Nevertheless the standard deviation of strength is relatively high on [0/90] specimens; such response is also observed by Aoki [16] and is inherent to axial compression response. This is explained by several phenomena:

- The possible slight misalignments of the 0 degrees plies from one layer or specimen to the other.

- The specimen end not being perfectly flat and parallel.

- A very small amount of specimen misalignment is inevitable.

Micrographs taken showed that 0 degrees plies could have a slight out of the plane waviness that would vary from specimen to specimen; this would reduce the axial compressive strength significantly and also increase the scatter.

To finish off the advantages and disadvantages of the new long gauge apparatus are listed below, with the advantages being:

- Possibility to check for misalignment in 3 dimensions.

- Full strain field on the specimen until compressive failure.

- Possibility to use the visual strain recordings as extensometer to check for misalignments.

- Full stress strain curves recordings in the axial direction.

- Full stress strain curves in compression shear.

- Images of the displacements and strains.

- The possibility to perform photo mechanics on the images to generate new fields.

- Very reproducible results on cross plies laminates.

- Permit the study of open hole specimen in compression.

- Possibility to use the rig in dynamic conditions. Also the disadvantages of the new apparatus are:

- The rig requires near perfect specimen preparation on [0/90] or [0] layups, (flat end, accurate layup, low laminate waviness (good manufacture)).

- Only the use of optical recording can be truly trusted with this set up as failure might occur away from the strain gauge location and the failure strain might exceed its capacity.

- Tabbing is required for improved load introduction.

- Low loading speed is required in the axial direction $(0.3 \mathrm{~mm} / \mathrm{min})$ as 1 or $2 \mathrm{~mm} / \mathrm{min}$ can be used in the bias direction. 


\section{Conclusions}

The new long gauge length apparatus provide a uniform strain field prior to damage of the material itself, that allows characterization of the material in compression with repeatable results in terms of stiffness and strength on the $[ \pm 45]$ laminate and on stiffness for [0/90]s but for this layup less repeatable results are observed on ultimate strength.

From a material point of view tufts reduce stiffness and strength by about $12 \%$ but prevent extensive specimen delamination in the axial direction. In the bias direction tufts oppose the shearing of the plies

The new compressive apparatus has shown to be a good alternative to previous setups. As the DIC usage evolves and improves, further understanding could be captured in compression. Further work has looked at dynamic compression testing with such apparatus and the generation of kinematic fields [24].

\section{Acknowledgements}

EU financial support through ITOOL/(ITOOL-FP6/ 516146), DICM equipment Limess Messtechnik and Software GmbH as well as Professor A. K. Pickett.

\section{REFERENCES}

[1] M. Colin de Verdiere, A. K. Pickett, A. A. Skordos and V. Witzel, "Evaluation of the Mechanical and Damage Behaviour of Tufted Non Crimped Fabric Composites Using Full Field Measurements," Composites Science and Technology, Vol. 69, No. 2, 2009, pp. 131-138. doi:10.1016/i.compscitech.2008.08.025

[2] An American National Standard, "Standard Test Method for Compressive Properties of Rigid Plastics, Designation: D695-91," Annual Book of ASTM Standards, Vol. 15-03.

[3] J. F. Harper, N. A. Miller and S. C. Yap, " Problems Associated with the Compression Testing of Fiber Reinforced Plastics Composites," Polymer Testing, Vol. 12 No. 1, 1993, pp. 15-29. doi:10.1016/0142-9418(93)90023-I

[4] R L. Westberg and M. G. Abdallah, "An Experimental and Analytical Evaluation of Three Compressive Test Methods for Unidirectional Graphite/Epoxy Composites," Proceeding of the 6th International Congress on Experimental Mechanics, Vol. 1, 1988, pp. 350-361.

[5] An American National Standard, "Standard Test Methods for Compressive Properties of Polymer Matrix Composite Material with Unsupported Gage Section by Shear Loading, Designation: D341/3410M-03," Annual Book of ASTM Standards, Vol 15-03.

[6] X. Ming and F. Adams, "Effect of Loading Method on Compression Testing of Composite Material," Journal of Composite Materials, Vol. 29, No. 12, 1995, pp. 15811600.
[7] D. H. Woolstencroft, A. R. Curtis and R. I. A. Haresceugh, "A Comparison of Tests Techniques Used for the Evaluation of the Unidirectional Compressive Strength of Carbon Fiber-Reinforced Plastic," Composites, Vol. 12, No. 4, 1981, pp. 275-280. doi:10.1016/0010-4361(81)90018-5

[8] D. F Adams and J. F. Welsh, "The Wyoming Combined Loading Compression (CLC) Test Method," Journal of Composites Technology \& Research, Vol. 19, No. 3, 1997 pp. 123-133. doi:10.1520/CTR10023J

[9] J. G. Haberle and F. L Matthews, "The Influence of Test Methods on the Compressive Strength of Several FiberReinforced Plastics," Journal of Advanced Materials, Vol. 25, No. 1, 1993, pp. 33-45.

[10] J. Häberle, "Strength and Failure Mechanisms of Unidirectional Carbon Fibre-Reinforced Plastic under Axial Compression," Ph.D. Thesis, Imperial College Technology and Medecine, London, 1991.

[11] "Standard Test Method for Determining the Compressive Properties of Polymer Matrix Composite Laminate Using a Combined Loading Compression (CLC) Test Fixture. Designation: D6641/D6641M," Annual Book of ASTM Standards, Vol. 15-03.

[12] D. F. Adams and E. Q. Lewis, "Influence of Specimen Gage Length and Loading Method on the Axial Compressive Strength of Unidirectional Composite Materials," Experimental Mechanics, Vol. 31, No. 1, 1991, pp. 14-20. doi:10.1007/BF02325717

[13] J. G. Haeberle and F. L. Matthews, "The Influence of Test Methods on the Compressive Strength of Several Fibber Reinforced Plastics," Journal of Advanced Materials, Vol. 25, No. 1, 1993 pp. 33-45.

[14] C. Seng and T. Tan, "Stress Analysis and the Testing of Celanese and IITRI Compression Specimens," Composites Science and Technology, Vol. 44, No. 1, 1992, pp. 57-70. doi:10.1016/0266-3538(92)90025-X

[15] P. Berbineau, C. Soutis and I. A. Guz, "Compressive Failure of 0 Degrees Unidirectional Carbon Fibre-Reinforced Plastics (CFRP) Laminates by Fibre Microbuckling" Composites Science and technology, Vol. 59, No. 9, 1999, pp. 1451-1455. doi:10.1016/S0266-3538(98)00181-X

[16] R. Aoki, J. T. Hart, H. Bookholt, P. T. Curtis, I. Kroeber, N. Marks and P. Sigety, "Compressive Strength of Various CFRP's Tested by Different Laboratories," National Aerospace Lab Amsterdam, Garteur Tp-c63 04/1993.

[17] C. A. Squires, K. H. Netting and A. R. Chambers, "Understanding the Factors Affecting the Compressive Testing of Unidirectional Carbon Fibre Composites," Composites Part B, Vol. 38, No. 4, 2007, pp. 481-487. doi:10.1016/j.compositesb.2006.08.002

[18] T. A. Bogetti, J. W. Gillespie and R. B. Pipes, "Evaluation of the IITRI Compression Test Method for Stiffness and Strength Determination," Composites Science and Technology, Vol. 32, No. 1, 1988, pp. 57-76. doi:10.1016/0266-3538(88)90029-2

[19] H. Nisitani, Y. H. Kim, H. Gotos and H. Nishitani, "Effect of Gage Length and Stress Concentration on the 
Compressive Strength of a Unidirectional CFRP," Engineering Frac ture Mechanics, Vol. 49, No. 6, 1988, pp. 953-961. doi:10.1016/0013-7944(94)90026-4

[20] A. G Salvi, A. M Waas and A. Caliskan, "Specimen Size Effects in the Off-Axis Compression Test of Unidirectional Carbon Fiber Tow Composites," Composites Science and Technology, Vol. 64, No. 1, 2004, pp. 83-97. doi:10.1016/S0266-3538(03)00214-8

[21] H. M. Hsiao and I. M. Daniel, "Effect of Fibre Waviness on Stiffness and Strength Reduction of Unidirectional Composites under Compressive Loading," Composites Science and Technology, Vol. 56, No. 5, 1996, pp. 581593. doi:10.1016/0266-3538(96)00045-0
[22] N. K. Naik and R. S. Kumar, "Compressive Strength of Unidirectional Composites: Evaluation and Comparison of Prediction Models," Composites Structures, Vol. 46, No. 3, 1999, pp. 299-308. doi:10.1016/S0263-8223(99)00098-7

[23] Y. L. Xu and K. L. Reifsnider. "Micromechanical Modeling of Composite Compressive Strength," Journal of Composite Materials, Vol. 27, No. 6, 1993, pp. 558-572.

[24] M. Colin de Verdiere, "Damage and Strain Rate Optical Characterization of Tutfted and Untufted Carbon Composites for Mesoscale Impact Models," Ph.D. Thesis, Cranfield University, Cranfield, 2009. 